\title{
IMPLEMENTASI PENDIDIKAN KARAKTER BERBASIS Al-QUR'AN DAN AS-SUNNAH: Studi Kasus Kelas 6 SD Al- Wildan Islamic School (Nurul Islam) Tangerang
}

\author{
Ubaidillah Alghifary Slamet | Syahida Rena | Ine Ratu Fadhilah \\ Dosen IIQ Jakarta \\ princessfortune77@gmail.com
}

\begin{abstract}
This type of research is qualitative research. Qualitative research is an intensive search using scientific procedures to produce narrative conclusions both written and oral based on analysis of certain data. Sources of data in research are the subjects from which data can be obtained, starting from key informants, namely school leaders, teachers, and students. The result of this research is character education based on al-Qur'an and Sunnah at SD Al-Wildan Islamic School (Nurul Islam) is the school's flagship program, the aim is to build noble characters according to the al-Qur'an and Sunnah in students through daily learning in class, supported by 3 national, international and Islamic boarding school curricula through a long process of stimulating character education since grade 1 so that in grade 6 it has become a child's character. The evaluation system for the evaluation of Quality Control (QC) students is strict, thenassessed and followed up on supporting programs, namely teacher training, socialization programs, parent visit class (PVC) programs, the tahfizh house program, with the formulation of values: (1) planting noble manners and morals, (2) environmental cleanliness, (3) Social society, (4) Awareness of worship, (5) love for the country. Implementation of the material can be seen in: (1) Welcoming students, (2) Guidance of homeroom teachers, (3) making classroom rules, (4) having lunch with class teachers, (5) holding class cleanliness and beauty competitions, (6) holding social service activities, (7) reading dhikr morning and evening, (8) duha prayer, (9) praying in congregation, (10), holding a ceremony. Supporting factors are teacher obedience and discipline in carrying out mandate tasks, leadership consistency, synergy between teachers, guardians and students. The inhibiting factor is the new students who do not have al-Qur'anic characteristics and cannot recite the Koran.
\end{abstract}

Keyword: character education; al-Qur'an; as-Sunnah 


\section{Abstrak}

Pendidikan karakter berbasis al-Qur'an dan as-Sunnah di SD Al-Wildan Islamic School (Nurul Islam) adalah program unggulan sekolah, tujuannya untuk pembentukan karakter mulia sesuai al-Qur'an dan as-Sunnah pada diri peserta didik melalui pembelajaran seharihari di kelas, didukung dengan 3 kurikulum nasional, internasional dan pesantren melalui proses stimulan pendidkan karakter yang lama sejak kelas 1 sehingga di kelas 6 sudah menjadi karakter anak. Sistem evaluasi penilaian Quality Control (QC) siswa yang ketat, kemudian di nilai dan di tindak lanjuti pada program-program pendukung yaitu pelatihan guru-guru, program sosialisasi, program parent visit class (PVC), program rumah tahfizh, dengan rumusan nilai: (1) penanaman adab dan akhlak yang mulia, (2) kebersihan lingkungan, (3) sosial Masyarakat, (4) kesadaran beribadah, (5) cinta tanah air. Implementasi materi dapat dilihat pada: (1) Penyambutan siswa, (2) Bimbingan Wali kelas, (3) membuat tata tertib dikelas, (4) makan siang bersama guru dikelas, (5) mengadakan lomba kebersihan dan keindahan kelas, (6) mengadakan kegiatan bakti sosial, (7) membaca zikir pagi dan petang, (8) shalat dhuha, (9) shalat berjamaah, (10), mengadakan upacara. Faktor pendukung yakni adanya ketaatan dan disiplin guru dalam menjalankan tugas amanah, konsistensi pimpinan, adanya sinergi antara guru, wali murid dan siswa. Faktor penghambat yakni siswa baru yang belum berkarakter al-Qur'an dan belum bisa mengaji.

Kata Kunci: pendidikan karakter; al-Qur'an; as-Sunnah 


\section{A. Pendahuluan}

Kondisi bangsa Indonesia saat ini, menunjukkan krisis karakter yang cukup memprihatinkan. Generasi penerus bangsa mengalami kasus dekadensi moral yang terjadi di lingkungan keluarga, sekolah, dan masyarakat. Gejala sosial tersebut telah sampai pada taraf meresahkan. Tidak jarang berita tentang perkelahian pelajar menjadi judul berita di media cetak, elektronik, dan lainnya. Tidak hanya itu, banyak kasus yang menunjukkan krisis karakter pada generasi muda yang kehidupannya hancur. Seperti halnya; narkoba, rusak karena pacaran, sibuk main game, jalan-jalan malam, ngerumpi, trek motor, merokok, budaya mencontek, tidak menghormati guru dan tidak patuh pada orang tua, merusak fasilitas umum, bullying, tawuran, dan melampiaskan kelulusan dengan mencorat coret baju seragam sekolah dan sebagainya. Sebaliknya bahkan pendidik pun bermasalah ada yang mengajak muridnya main game mobile legend di kelas ketika pembelajaran berlangsung. Bahkan sampai kepada orang tua sebagai pendidik pertama dan dirumah tak lepas dari masalah dalam mendidik anaknya dengan mengabaikan pendidikan akhlak anak.

Indonesia menanamkan nilai-nilai karakter dalam pendidikan agama melalui pendidikan karakter di sekolah. Prinsip mendasar tentang pengembangan karakter di Indonesia ada pada rumusan fungsi dan tujuan Pendidikan Nasional, Pasal 3 Undang-Undang Nomor 20 Tahun 2003 tentang Sistem Pendidikan Nasional; Pendidikan Nasional berfungsi mengembangkan kemampuan dan membentuk watak serta peradaban bangsa yang bermartabat dalam rangka mencerdaskan kehidupan bangsa, bertujuan untuk berkembangnya potensi peserta didik agar menjadi manusia yang beriman dan bertakwa kepada Tuhan Yang Maha Esa, berakhlak mulia, sehat, berilmu, cakap, kreatif, mandiri, dan menjadi warga negara yang demokratis serta bertanggung jawab. ${ }^{1}$ Pendidikan karakter dengan nilai-nilai akhlakul karimah berbasis al-Qur'an dan as-Sunnah dalam kerangka kurikulum 2013 dilandasi oleh firman Allah Swt (Q.S. al-Baqarah (2): 269.;

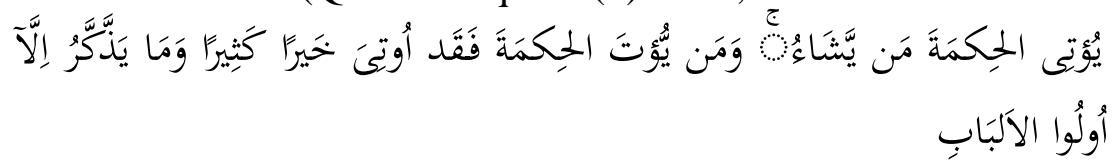

${ }^{1}$ Undang-Undang Nomor 20 Tahun 2003 tentang Sistem Pendidikan Nasional, Bab I, Pasal 3. 
Implementasi Pendidikan Karakter Berbasis al-Qur'an dan as-Sunnah: Studi Kasus Kelas 6 SD al-Wildan Islamic School(N)urul Islam) Tangerang |

Artinya: "Allah menganugerahkan al hikmah (kefahaman yang dalam tentang al-Qur'an dan as-Sunnah) kepada siapa yang dikehendaki-Nya. Dan barangsiapa yang dianugerahi hikmah, ia benar-benar telah dianugerahi karunia yang banyak. Dan hanya orang-orang yang berakallah yang dapat mengambil pelajaran (dari firman Allah)."

Seorang muslim harus membangun karakter mulia di lingkungannya. Gambaran karakter Islam yang patut kita jadikan tolak ukur adalah karakter Rasulullah, sebagai cerminan dari alQur'an dan as-Sunnah yang disaksikan oleh para sahabat Rasul dan harus dijadikan suri tauladan bagi umatnya. Allah Swt, berfirman (Q.S. al-Ahzab (33): 21.;

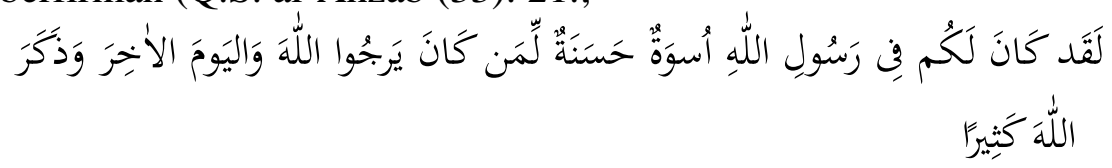

Artinya: "Sesungguhnya telah ada pada (diri) Rasulullah itu suri teladan yang baik bagimu (yaitu) bagi orang yang mengharap (rahmat) Allah dan (kedatangan) hari kiamat dan dia banyak menyebut Allah.

Sejak anak masuk Sekolah Dasar hingga ke usia adolesense (remaja awal dan akhir), ide ketuhanan, anak sudah mencerminkan konsep-konsep yang berdasarkan kepada realitas. ${ }^{2}$ Pendidikan karakter Islam sebagai pondasi umat muslim harus diperkuat konsep dasarnya.

Karakter dalam perspektif Islam bukan hanya hasil pemikiran dan tidak berarti lepas dari realitas kehidupan tetapi merupakan persoalan yang terkait dengan napsu, akal, ruh, hati, jiwa, realitas dan tujuan yang digariskan oleh akhlak Qur'aniah. ${ }^{3}$ Pendidikan karakter sudah sejak lama diajarkan Allah Swt. melalui firman-firman-Nya dan diimplementasikan umat muslim sejak zaman Nabi Adam As hingga Nabi Muhammad Saw. Tidak ada persoalan dalam kehidupan yang luput dalam pembahasan al-Qur'an, termasuk segala hal terkait pendidikan karakter diajarkan dalam Islam.

${ }^{2}$ Bambang Syamsul Arifin, Psikologi Agama, cet. Ke-2, (Bandung: CV. Pustaka Setia, 2015), 50.

${ }^{3}$ Ali Khalil Abu Ainain, Falsafah at-Tarbiyah fi al-Qur'an al-Karim (Kairo: Der Al-Fikr Al-Arabi, 1985), 186. 
Implementasi Pendidikan Karakter Berbasis al-Qur'an dan as-Sunnah: Studi Kasus Kelas 6 SD al-Wildan Islamic School(N)urul Islam) Tangerang |

Sunnatullah atau hukum Allah yang menyebabkan alam semesta selaras, serasi dan seimbang dipatuhi sepenuhnya oleh partikel atau zarrah yang menjadi unsur alam semesta ini. Ada tiga sifat utama sunnatullah yang disinggung dalam alQur'an yang dapat ditemukan oleh ahli ilmu pengetahuan dalam penelitian. Ketiga sifat itu adalah pasti, tetap dan objektif. ${ }^{4}$ Pertama adalah pasti yang berarti ketetapan, ketentuan, atau kepastian, dalam QS. at-Thalaq (65): 3 Allah Swt, berfirman;

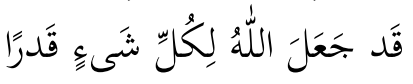

Artinya:"...Sesungguhnya Allah telah mengadakan ketentuan bagi tiap-tiap sesuatu."

Kedua adalah tetap, yaitu tidak berubah-ubah. ${ }^{5}$ Sifat ini diungkapkan dalam QS. al-Isra (17): 77, firman-Nya;

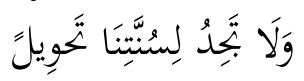

Artinya: "...dan tidak akan engkau dapati perubahan atas ketetapan Kami.

Ketiga adalah obyektif. Sifat ini tergambar pada QS. arRad (13): 11) firman Allah;

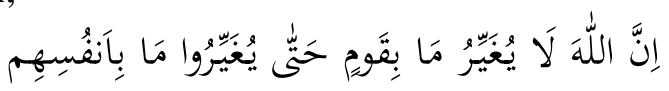

Artinya: “...Sesungguhnya Allah tidak akan mengubah keadaan suatu kaum sebelum mereka mengubah keadaan diri mereka sendiri..."

Ketiga karakter utama sunnatullah tidak terbangun dengan sendirinya, melainkan harus dibentuk dan ditumbuh kembangkan melalui pendidikan akan berjalan efektif dan utuh jika melibatkan tiga institusi yaitu keluarga, sekolah, dan masyarakat. ${ }^{6}$ Lingkungan yang jelek tidak hanya menghalangi tercapainya tujuan pendidikan, akan tetapi juga akan merusak karakter peserta didik yang dibangun melalui proses pembelajaran di kelas. ${ }^{7}$

${ }^{4}$ Somad Zawawi, dkk., Membangun Etika Islam dalam Kehidupan (Jakarta: Penerbit Universitas Trisakti,2015), 3.

${ }^{5}$ Somad Zawawi, dkk., Membangun Etika Islam dalam Kehidupan (Jakarta: Penerbit Universitas Trisakti,2015), 4.

${ }^{6}$ Amirulloh Syarbini, Model Pendidikan Karakter dalam Keluarga (Jakarta: PT. Elex Media Komputindo, 2014), 3.

${ }^{7}$ Janer Sinarmata, et. al., Inovasi Pendidikan Lewat Transformasi Digital (Medan: Yayasan Kita Menulis, 2019), 80. 
Oleh karena itu, perlu dilakukan penelitian dan kajian lebih mendalam untuk mengetahui implementasi pendidikan karakter pada kurikulum sekolah di berbagai jenis jenjang pendidikan.

Salah satu sekolah yang mengimplementasikan kurikulum berbasis al-Qur'an dan as-Sunnah dalam penguatan pendidikan karakter adalah Sekolah Dasar (SD) Al-Wildan Islamic School (Nurul Islam). Sekolah yang berada di kawasan BSD tepatnya di Gading Serpong Tangerang ini, sudah berdiri sejak tahun 2014-2015 dan sudah meluluskan lima angkatan. Sekolah ini terakreditasi A bernilai 95, mencetak hafizhhafizhah (penghafal) al-Qur'an bersanad melalui salah satu kurikulum pendukungnya yaitu TIC (Tahfizh al-Qur'an and International Curriculum) yakni tahfizh al-Qur'an dan kurikulum internasional. Kurikulum Internasional (Kurikulum negara anggota OECD). Target mutu output yang diharapkan SD Al-Wildan Islamic School (Nurul Islam) Tangerang yang terkait dengan tema penelitian yaitu; siswa dapat memiliki karakter akhlak yang mulia kepada orang tua (birrul walidain) dan akhlak memuliakan guru dan menghormati orang lain. Guru sebagai komponen utama dalam pendidikan di sekolah, bertugas mengajarkan pendidikan karakter Islam untuk membentuk peserta didik berakhlakul karimah sesuai al-Qur'an dan As-Sunnah.

Sekolah Sunnah SD Al-Wildan Islamic School (Nurul Islam) hadir di lingkungan Bumi Serpong Damai, di tengah menjamurnya sekolah non muslim yang bertaraf internasional dengan fasilitas yang representatif serta masyarakatnya yang multikultural. Untuk dapat memecahkan masalah Implementasi Pendidikan Karakter Berbasis al-Qur'an dan as-Sunnah penelitian kali ini akan digunakan metode kualitatif deskriptif. 


\section{B. Metode Penelitian}

1) Jenis Dan Pendekatan Penelitian

Penelitian ini menggunakan jenis penelitian kualitatif. Penelitian kualitatif adalah suatu proses penelitian yang dilakukan secara wajar dan natural sesuai dengan kondisi objektif di lapangan tanpa adanya manipulasi, serta jenis data yang dikumpulkan terutama data kualitatif. ${ }^{8}$ Dalam penelitian kualitatif, teori yang digunakan dalam penyusunan proposal penelitian kualitatif juga masih bersifat sementara, dan akan berkembang setelah peneliti memasuki lapangan atau konteks sosial. Dalam kaitannya dengan teori dalam penelitian kualitatif bersifat menemukan teori. $^{9}$

Penelitian ini melakukan observasi terhadap orang dalam kehidupannya sehari-hari, berinteraksi dengan mereka, dan berusaha memahami bahasa dan tafsiran mereka tentang dunia dan sekitarnya. Dalam penelitian ini, penulis menggunakan metode penelitian field research (penelitian lapangan) yaitu penelitian dengan melakukan pengamatan secara langsung terhadap objek penelitian, untuk memperoleh informasi terhadap masalah-masalah yang dibahas.

Metode penelitian yang akan dilakukan peneliti menggunakan pendekatan kualitatif. Sri Mamudji mengemukakan bahwa pendekatan kualitatif merupakan tata cara penelitian yang menghasilkan data deskriptif analitis, yaitu apa yang dinyatakan oleh sasaran penelitian yang bersangkutan secara tertulis atau lisan, dan perilaku nyata. Yang diteliti dan dipelajari adalah obyek penelitian yang utuh. $^{10}$ Pendekatan penelitian ini menggunakan pendekatan penelitian kualitatif deskriptif, yaitu penelitian yang digunakan untuk mendeskripsikan dan menjawab persoalan-persoalan suatu fonomena atau peristiwa yang terjadi saat ini.

${ }^{8}$ Theresia Kristianty, Metode Penelitian Kualitatif dan Enam Tradisi Penelitian Kualitatif (Jakarta: Balai Pustaka, 2003), 7.

9 Sugiyono, Metode Penelitian Kuantitatif, Kualitatif, dan $R \& D$ (Bandung: Alfabeta, 2016), 213.

${ }^{10}$ Sri Mamudji, dkk., Metode Penelitian dan Penulisan Hukum (Depok: Fakultas Hukum Universitas Indonesia, 2005), 67. 
Implementasi Pendidikan Karakter Berbasis al-Qur'an dan as-Sunnah: Studi Kasus Kelas 6 SD al-Wildan Islamic School(N)urul Islam) Tangerang |

Penelitian akan dimulai pada akhir bulan Mei hingga 12 Agustus 2020 sampai selesai. Lokasi penelitian yang dijadikan objek oleh peneliti yaitu di Sekolah Dasar (SD) Al-Wildan Islamic School (Nurul Islam) Tangerang yang beralamat di J1. Bidar I No. 2, Kelapa Dua, Kec. Kelapa Dua, Tangerang, Banten 15810.

Dalam penelitian kualitatif, peneliti merupakan instrument utama dalam mengumpulkan data dan menginterpreasikan data dengan dibimbing oleh pedoman wawancara. Sehingga dapat memahami makna interaksi sosial, mendalami nilai-nilai yang tergambar dalam ucapan dan perilaku responden. Adapun penelitian ini terarah, peneliti lebih dahulu menyusun indikator instrument yang selanjutnya dijadikan acuan untuk membuat pedoman wawancara. Adapun indikator untuk pedoman wawancara adalah sebagai berikut:

Tabel 1.1 Indikator Pedoman Wawancara

\begin{tabular}{|c|l|}
\hline No & \multicolumn{1}{|c|}{ Indikator } \\
\hline \hline 1 & $\begin{array}{l}\text { Perencanaan implementasi Pendidikan karakter } \\
\text { berbasis al-Qur'an dan as-Sunnah }\end{array}$ \\
\hline 2 & $\begin{array}{l}\text { Langkah-langkah yang dilaksanakan dalam } \\
\text { implementasi pendidikan karakter berbasis al- } \\
\text { Qur'an dan as-Sunnah }\end{array}$ \\
\hline 3 & $\begin{array}{l}\text { Metode yang digunakan dalam implementasi } \\
\text { pendidikan karakter berbasis al-Qur'an dan as- } \\
\text { Sunnah }\end{array}$ \\
\hline 4 & $\begin{array}{l}\text { Media dalam pelaksanaan implementasi } \\
\text { pendidikan karakter berbasis al-Qur'an dan as- } \\
\text { Sunnah }\end{array}$ \\
\hline 5 & $\begin{array}{l}\text { Penilaian dan evaluasi implementasi pendidikan } \\
\text { karakter berbasis al-Qur'an dan as-Sunnah }\end{array}$ \\
\hline 6 & $\begin{array}{l}\text { Faktor pendukung dan penghambat yang terjadi } \\
\text { dalam implementasi pendidikan karakter berbasis al- } \\
\text { Qur'an dan as-Sunnah }\end{array}$ \\
\hline
\end{tabular}


Untuk dapat memperoleh suatu pemahaman yang mendalam terhadap objek penelitian yang diamati, maka pengumpulan dilakukan dengan cara:

a) Observasi

Observasi atau pengamatan sebagai alat penilaian untuk mengukur tingkah laku individu atau proses terjadinya suatu kegiatan yang dapat diamati. Ada tiga jenis observasi yakni observasi langsung, observasi dengan alat (tidak langsung) dan observasi partisipasi. Observasi langsung adalah pengamatan yang dilakukan terhadap gejala atau proses yang terjadi dalam situasi yang sebenarnya dan langsung diamati oleh pengamat. ${ }^{11}$ Metode observasi merupakan cara yang sangat baik untuk mengawasi perilaku subjek penelitian seperti perilaku dalam lingkungan atau ruang, waktu dan keadaan tertentu. ${ }^{12}$

b) Wawancara

Wawancara atau interview sebagai metode pengumpulan data yang dilaksanakan secara lisan dan pertemuan tatap muka yang baik secara individual atau kelompok. ${ }^{13}$ Teknik yang digunakan penulis adalah teknik wawancara bebas terpimpin yaitu pertanyaan yang diajukan telah dipersiapkan sebelumnya dengan cermat dan lengkap, namun penyampaian bebas tanpa terikat oleh nomor urut yang telah digariskan. ${ }^{14}$

${ }^{11}$ Nana Sudjana, Penilaian Hasil Proses Belajar Mengajar, cet. Ke-10 (Bandung: PT Remaja Rosdakarya, 2005), 85.

${ }^{12}$ Ida Bagoes Mantra, Filsafat Penelitian \& Metode Penelitian Sosial (Yogyakarta: Pustaka Pelajar, 2008), 79.

${ }_{13}^{13}$ Nana Syaodih Sukmadinata, Metode Penelitian Pendidikan., 216.

${ }^{14}$ Kartini Kartono, Pengantar Metodologi Riset (Bandung: Mandar Maju, 1990), 204. 
c) Dokumentasi

Metode dokumentasi yaitu metode pengumpulan data dengan mencari data mengenai hal-hal atau variabel yang berupa catatan, transkip, buku, surat kabar, majalah, dan sebagainnya. ${ }^{15}$ Metode dokumentasi adalah cara mengumpulkan data melalui benda-benda tertulis seperti peraturan-peraturan, notulen, catatan harian, dan lain-lain. ${ }^{16}$

Tehnik analisis data kualitatif menurut Bogdan dan Biklen adalah upaya yang dilakukan dengan jalan bekerja dengan data, mengorganisasikan data, emilah-milah data menjadi satuan yang dapat dikelola, mensintesiskannya, mencari, dan menemukan pola, menemukan apa yang penting dan apa yang dipelajari dan memutuskn apa yang dapat diceritakan kepada orang lain. ${ }^{17}$

Analisis data dalam penelitian kualitatif dilakukan pada saat pengumpulan data seperti yang dikemukakan oleh Miles dan Huberman bahwa aktivitas dalam analisis data kualitatif dilakukan secara interaktif dan berlangsung secara terus menerus sampai tuntas, sehingga datanya jenuh. ${ }^{18}$ Tehnik analisis Miles dan Huberman meliputi:

\section{Gambar 1.2. Tehnik analisis Miles dan Huberman}

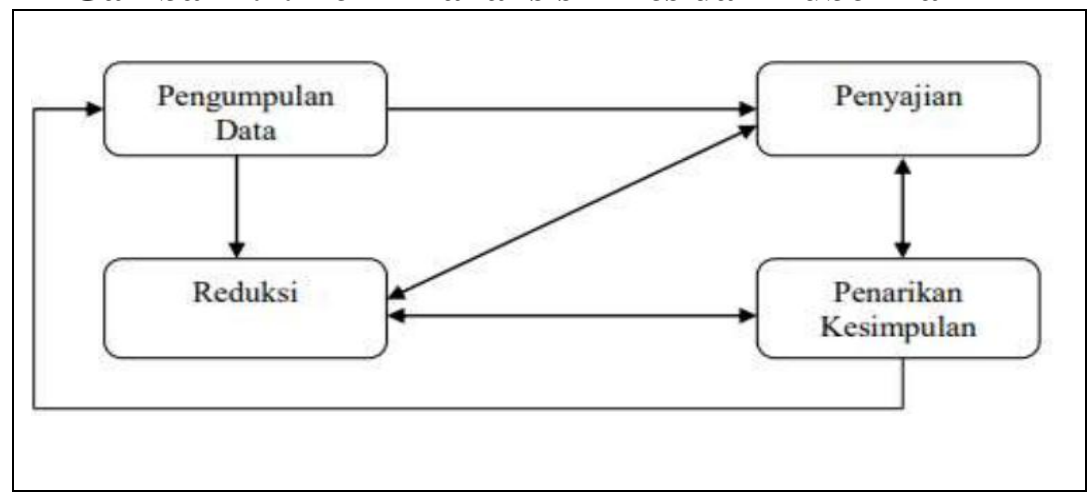

${ }^{15}$ Suharsimi Arikunto, Prosedur Penelitian Suatu Pendekatan Praktik (Jakarta: Rineka Cipta, 2014), 206.

${ }^{16}$ Suharsimi Arikunto, Prosedur Penelitian Suatu Pendekatan Praktik (Jakarta: Rineka Cipta, 2014),131.

17 Sugiyono, Metode Penelitian Kuantitatif Kualitatif dan $R \& D$ (Bandung: Alfabeta, 2012), 245.

18 Sugiyono, Metode Penelitian Kuantitatif Kualitatif dan $R \& D$ (Bandung: Alfabeta, 2012), 243. 
2) Aktivitas dalam menganalisis data kualitatif yaitu:

a) Reduksi Data (data reduction).

Mereduksi data berarti merangkum, memilih hal-hal yang pokok, memfokuskan pada hal-hal yang penting, dicari tema dan polanya. Dengan demikian data yang telah direduksi Secara teknis, pada kegiatan reduksi data yang telah dilakukan dalam penelitian ini meliputi: perekapan hasil wawanacara kemudian pengamatan hasil pengumpulan dokumen yang berhubungan dengan fokus penelitian.

b) Penyajian Data (data display)

Menyajikan data yaitu penyusunan sekumpulan informasi yang memberi kemungkinan adanya penarikan kesimpulan dan penarikan tindakan. Dalam penelitian kualitatif, penyajian data bisa dilakukan dalam bentuk uraian singkat, bagan, hubungan antar kategori, flowchart atau sejenisnya.

3) Penarikan Kesimpulan (conclusion drawing)

Langkah ketiga dalam analisis data menurut Miles dan Huberman adalah penarikan kesimpulan dan verifikasi. Kesimpulan dalam penelitian kualitatif adalah merupakan temuan baru yang sebelumnya belum pernah ada. 
Implementasi Pendidikan Karakter Berbasis al-Qur'an dan as-Sunnah: Studi Kasus Kelas 6 SD al-Wildan Islamic School(N)urul Islam) Tangerang |

\section{Pendidikan Karakter Berbasis al-Qur'an dan as-Sunnah di Al- Wildan Islamic School (Nurul Iman) Tangerang}

Sejalan dengan kutipan peneliti al-Maghribi bin asSa'id al-Maghribi, menjelaskan dalam bukunya "Begini Seharusnya Mendidik Anak", al-Qur'an diturunkan oleh Dzat Yang Maha Tinggi dan Maha Mampu, kepada Nabi terbaik dan penutup para nabi, Muhammad Saw agar menjadi landasan dan petunjuk bagi setiap manusia, yang mengeluarkan mereka dari kegelapan menuju cahaya Islam. ${ }^{19}$ Al-Qur'an dijadikan sebagai rujukan utama dalam mengembangkan nilai-nilai karakter, terutama dalam proses edukasi pendidikan karakter anak-anak di lingkungan keluarga, sekolah maupun masyarakat.

Dari hasil data wawancara dengan bapak Sahid (kepala sekolah), ${ }^{20}$ dapat dinarasikan bahwa:

a) Tujuan Pendidikan Karakter di Al-Wildan

Dalam pembentukan karakter mulia dalam diri peserta didik melalui pembelajaran sehari-hari di kelas, dan diaktualisasikan melalui pembiasaan kehidupan sehari-hari di rumah. Yang bersumber dari al-Qur'an dan As-Sunnah. diberikan pemahaman ayat al-Qur'an (al-Qalam (68): 4). sebagai berikut:

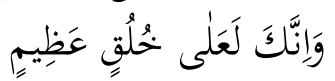

Artinya: "Dan sesungguhnya kamu benar-benar berbudi pekerti yang agung."

Ayat di atas diajarkan, difahamkan, kepada guru di AlWildan sebagai pendidik Islam. Yang tentunya dengan tujuan agar dapat sejalan dengan penanaman pendidikan karakter di sekolah. bapak kepala sekolah menambahkan bahwa Allah Swt menuntut hamba-Nya untuk mengerjakan dan memprioritaskan ibadah serta kegiatan yang berkualitas.

${ }^{19}$ Al-Maghribi bin as-Sa'id al-Maghribi, Begini Seharusnya Mendidik Anak, terj. Zainal Abidin Syamsuddin (Jakarta: Darul Haq, 2018), 156.

${ }^{20}$ Wawancara ke-1 kepada Ustad Sahid, hari Jum'at Tanggal 1 Mei 2020 Jam 10.00 di sekolah Al-Wildan Islamic School (Nurul Iman) Tangerang. 
b) Kurikulum Pendidikan Karakter kelas VI di Al-Wildan Islamic School (Nurul Iman) Tangerang.

Dari hasil wawancara mendalam dengan kepala sekolah ${ }^{21}$ dan hasil dari study dokumen, ${ }^{22}$ bahwa di sekolah ini memiliki kurikulum yakni: Tahfizh Al-Quran International Curriculum (TIC): The Primary Spirit of Education is a quality curriculum, because the Al-Wildan Islamic School.

c) Proses Pendidikan Karakter kelas VI di Al-Wildan Islamic School (Nurul Iman) Tangerang

Wawancara dengan bapak Sahid Abdullah, Lc pada acara sosialisasi, ${ }^{23}$ dijelaskan bahwa: 1) Metode pengajaran Pendidikan karakter pada siswa Metodologi pembelajaran yaitu dengan menggunakan metode Step And Elicit yaitu sangat mudah menumbuhkan motivasi dan kemampuan siswa dengan pendekatan Mastery Learning (belajar tuntas atau penguasaan penuh).

d) Evaluasi Pendidikan Karakter kelas 6 di Sekolah Dasar (SD)

Al-Wildan Islamic School (Nurul Iman) Tangerang

Dari data sosialisasi, ${ }^{24}$ evaluasi dilakukan setiap 3 bulan (mid semester) dan setiap semester (ujian Semester atau kenaikan kelas). Setiap akhir tahun akan diadakan ujian mutu bertulis dan lisan menggunakan bahasa Arab bagi setiap siswa yang dilakukan dengan mengundang penguji dari luar AlWildan Islamic School dan wajib di hadiri dan disaksikan langsung oleh orang tua/wali mudrid masing-masing dalam kegiatan Examination Authority (EXOT). Lanjutan dari pendapat ustad, program evaluasi juga dilakukan yang di sebut QC (Quality Control) penjelasannya berikut ini, bermula wali murid mengisi angket online setiap hari kemudian dikirmkan, lalu dievaluasi oleh guru. Berikut ini isi Quality Control (QC) dapat dilihat pada gambar berikut:

${ }^{21}$ Wawancara tambahan dengan bapak Sahid, hari kamis, 6 Agustus 2020, Jam 15.00.

${ }^{22}$ Power poin materi sosialisasi oleh ustad Sahid, tanggal 6 mei 2020. Lihat dilampiran 8 dan Wawancara ke-1 kepada Ustad Sahid, hari Jum'at Tanggal 1 Mei 2020 Jam 10.00 di sekolah Al-Wildan Islamic School (Nurul Iman) Tangerang.

${ }^{23}$ Power poin materi sosialisasi oleh ustad Sahid, tanggal 6 mei 2020, lihat dilampiran 8 .

${ }^{24}$ Power poin materi sosialisasi oleh ustad Sahid, tanggal 6 mei 2020. Lihat dilampiran 8. 
Gambar 1.3. Quality Control (QC)

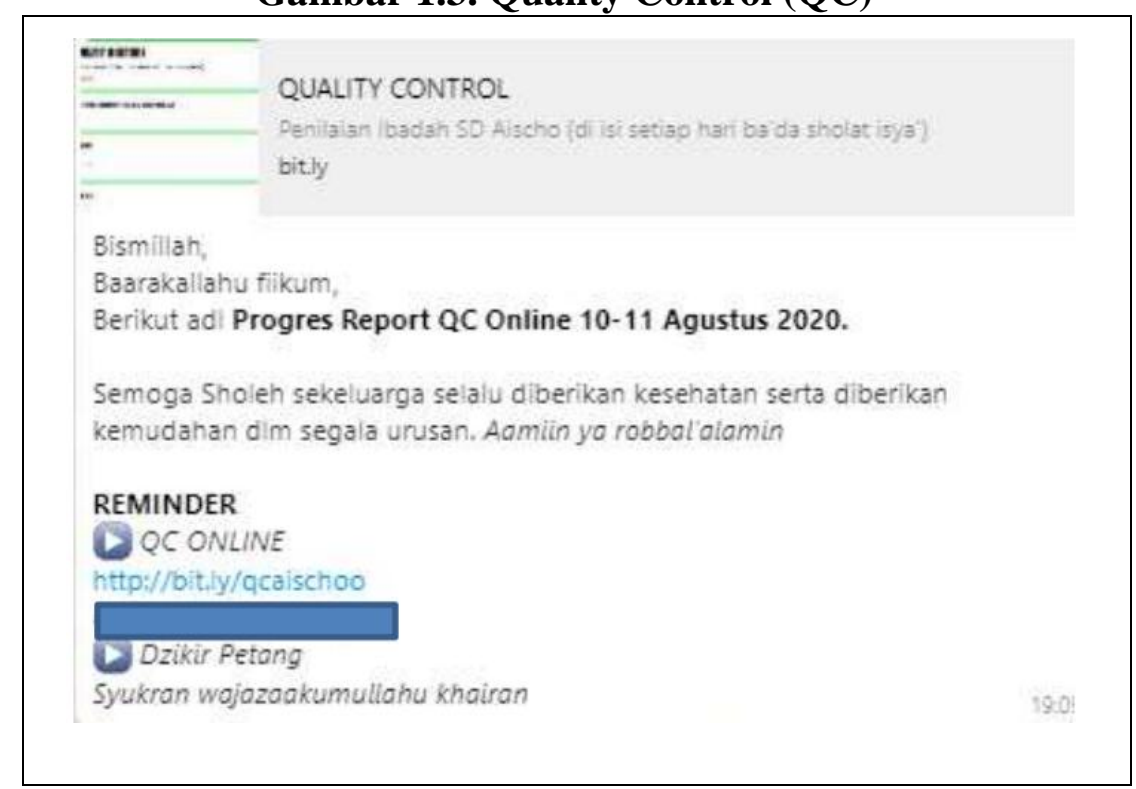

Isi penilaian QC adalah: penilaian Ibadah, ini diisi oleh seluruh siswa dari kelas 1 sampai dengan kelas 6. Khusus kelas 6, yakni dzikir pagi, duha salat zuhur, ba'diyah dzuhur, qobliyah zuhur, salat asar, dzikir petang, shalat magrib, ba'diyah magrib, salat isya, ba'diyah isya, dzikir setelah salat. Kemudian penilaian kesehatan, isisnya: setiap hari ba'da isya minum air mineral minimal 2 liter, cuci tangan pakai sabun dengan air mengalir,bangun tidurnya jam berapa.

Selanjutnya kesadaran beribadah disesuaikan dengan tingkatan umur dan kelas siswa. Peneliti diperlihatkan capaian ibadah sesuai kelas nya pada gambar QC berikut: 


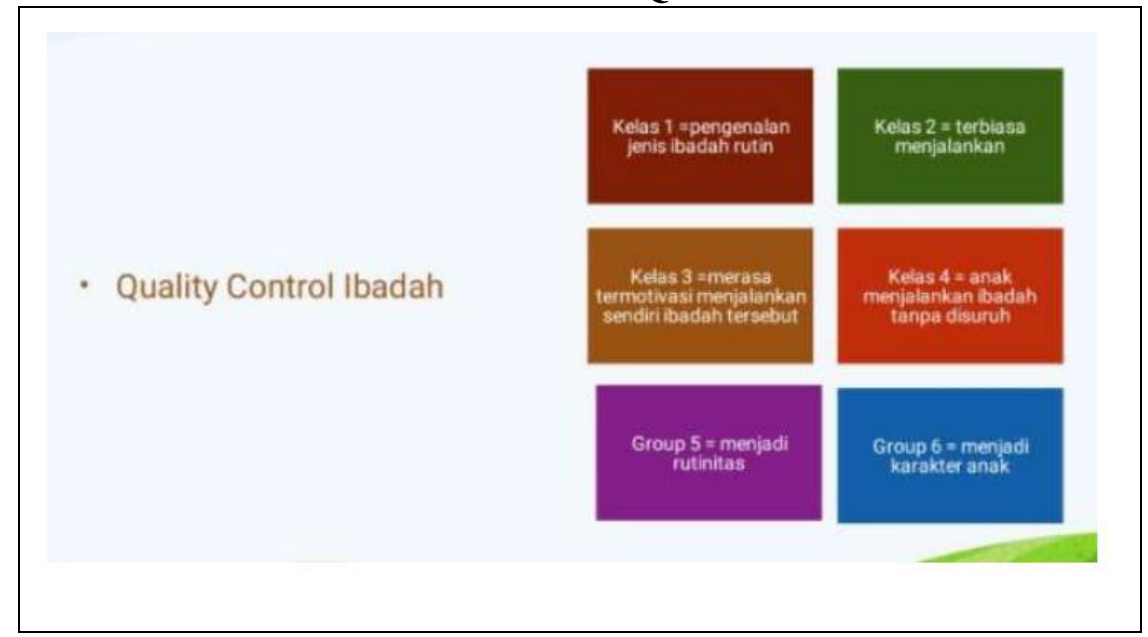

Pada hasil wawancara, bapak kepala sekolahnya mengatakan;" "Insya Allah akan menerapkan kesadaran beribadah itu dari awal kelas 1 sampai anak-anak kelas 6 dengan menggunakan quality control. Kita mempunyai tahapantahapannya didasarkan pada kelas. Untuk kelas 6 kita jadikan karakter yang mana karakter itu membutuhkan waktu yang cukup lama agar anak-anaknya menjadi sebuah karakter pada diri mereka sendiri.

${ }^{25}$ Wawancara lanjutan kepada bapak Sahid, hari Rabu, tanggal 12 Agustus 2020 jam 08.00, menggunakan failitas Whats Up (WA) dengan Voice Note. 
Implementasi Pendidikan Karakter Berbasis al-Qur'an dan as-Sunnah: Studi Kasus Kelas 6 SD al-Wildan Islamic School (N Uurul Islam) Tangerang |

D. Implementasi Materi Pembelajaran Terkait Pendidikan Karakter Berbasis al-Qur'an dan as-Sunnah di Kelas 6 Sekolah Dasar (SD) Al-Wildan Islamic School (Nurul Islam) Tangerang

Berdasarkan analisis data peneliti menyimpulkan bahwa implementasi materi pembelajaran Pendidikan karakter berbasis al-Qur'an dan as-Sunnah masuk dalam kegiatan sekolah, mulai dari kedatangan pagi hari hingga kepulangan siswa, kegiatan tersebut adalah:

1. Penyambutan Siswa Saat Pagi Oleh Semua Guru

Setiap pagi hari guru lebih dulu datang dari pada siswa, untuk menumbuhkan semangat siswa dalam menuntut ilmu maka guru disekolah ini menerapkan penyambutan siswa yang datang ke sekolah dengan memberikan penghargaan pujian terbaik karena datang tepat waktu, bersalaman, dan mengucapkan salam. Datang tepat waktu adalah sikap terbaik dan sebagai pelajar muslim amalan terbaiknya "harus disiplin waktu". Dan Serta guru menyapa siswa dengan senyuman terbaik. Sambil menyapa dengan ucapan "sudah sedekah belum pagi ini" ini sindiran agar siswa memberikan senyuman balik jika dia lupa tersenyum. Sebagaimana pengamalan hadis tentang senyum adalah sedekah.

2. Bimbingan Wali Kelas 20 Menit Pertama Setiap Hari

Program ini dimasukkan dalam jadwal yang dinamakan rise $n$ shine. Bersama "walas" (dalam menyebut wali kelas). Berisi kegiatan quantum agama yakni penguatan stimulan tentang ketaatan ilahiyah dan amalan sunnah serta ridha orang tua.

Memotivasi agar semangat menjadi manusia yang ahli al-Qur'an dan sunnah, yang berbeda dengan orang biasa yang tanpa memiliki kemampuan ilmu al-Qur'an dan as-Sunnah. Disini siswa disadarkan bahwa manusia terbaik adalah yang tau al-Quran dan sunnah serta mengamalannya. Seperti gambar berikut buku zikir yang digunakan, dan kondisi siswa sedang dalam bimbingan wali kelas sekaligus juga baca al-Qur'an. 
Implementasi Pendidikan Karakter Berbasis al-Qur'an dan as-Sunnah: Studi Kasus Kelas 6 SD al-Wildan Islamic School(N)urul Islam) Tangerang |

Gambar 5.1. Kondisi Siswa sedang dalam Bimbingan Wali

Kelas

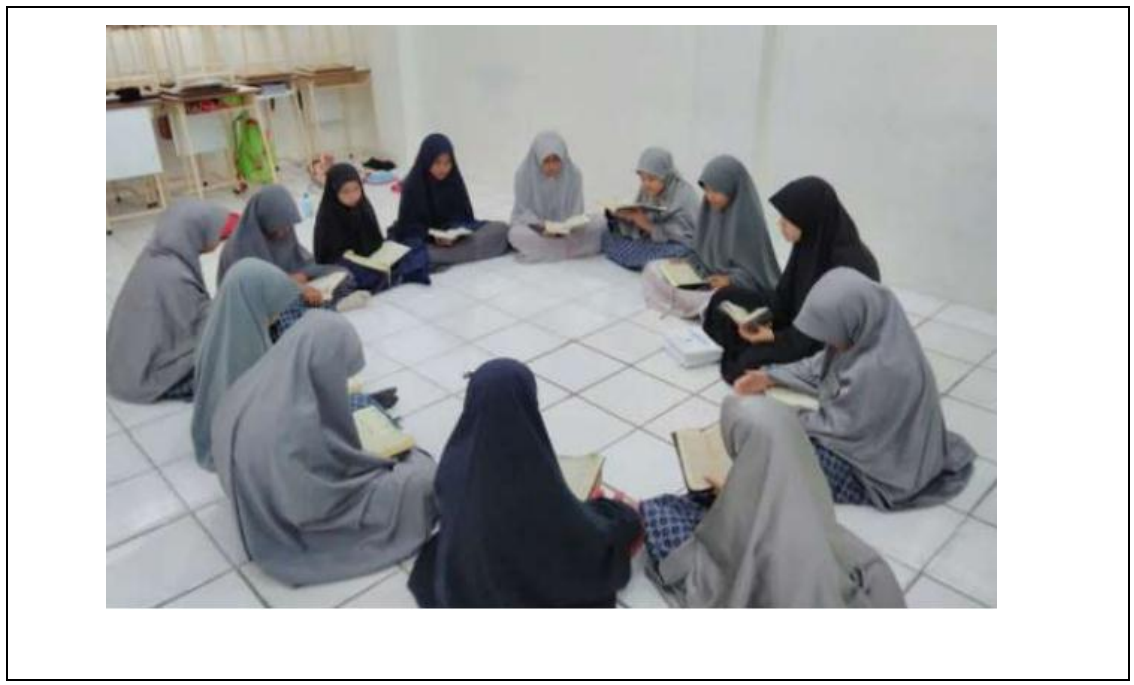

3. Membuat Tata Tertib di Kelas

Dengan dipandu oleh guru siswa dibantu untuk membuat tata tertib dikelas masing masing, dan ditaati bersama-sama bersadarkan kesepakatan bersama. Mengatur jadwal piket menjaga kebersihan kelas. Membuang sampah. dan menyusun kerapihan kelas. Ini dinilai oleh guru dalam perlombaan kebersihan dan keindahan kelas. Puncak acaranya digabungkan dalam acara market day, berisi interprenership, kebersihan kelas, dan lomba menghias kelas.

Gambar 6.1. Market Day

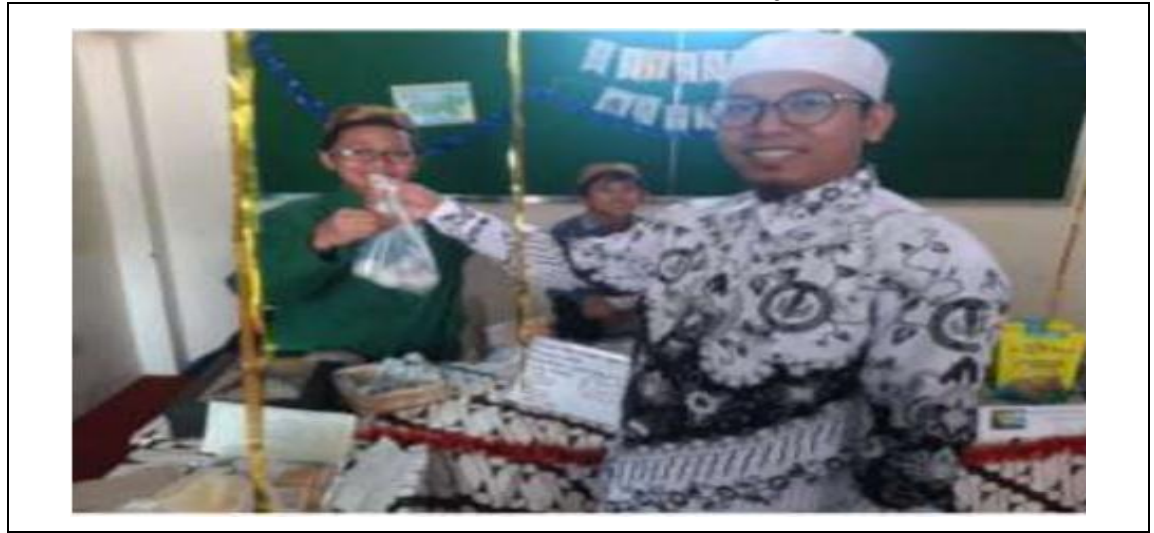

4. Makan Siang Bersama Guru

Siswa membawa bekal masing-masing dan begitu juga guru dari catering sekolah. Makan bersama siswa dikelas masing masing. Berdoa sebelum makan dipimpin oleh salah satu siswa. 
5. Mengadakan Lomba Kebersihan dan Keindahan Kelas.

Lomba ini dipersiapkan sejak jauh hari, tiap tahun ajaran baru, dan sudah disusun dalam jadwal tata tertib yang sudah disepakati bersama. Dikemudian hari tertentu tanpa diberitahukan waktunya guru menilai kebersihan kelas masing masing akan dinilai oleh guru yang sudah ditunjuk oleh sekolah.

6. Mengadakan Kegiatan Bakti Sosial Untuk Anak Yatim dan Duafa

Di kelas disediakan kotak sosial. Seperti celengan, yang diisi setiap seminggu sekali. Adapun dipersilahkan bagi yang ingin mengisi kotak infaq setiap hari. Kotak infaq ini ditulis dengan gambar akan di sumbangkan ke mana. Dengan target yang ditentukan. Biasanya dibantu oleh wali murid, yang setiap ada bencana atau musibah untuk didonasikan.

7. Membaca Dzikir Pagi dan Petang Setiap Hari

Biasanya shalat dhuha dan dilanjutkan dengan penunjukan siswa untuk memimpin menjadi imam, bertugas memberikan kultum dan memimpin bacaan doa dan zikir pagi. Dan sebaktu sore sebelum pulang sekolah siswa shalat asahar langsung baca zikir sore.

8. Melaksanakan Shalat Duha Setiap Hari

shalat dhuha dilaksanakan setiap hari, siswa di berikan kesempatan untuk memimpin menjadi imam, kultum dan memimpin mengaji pada waktu selesai melaksanakan dhuha. Kadang dilaksanakan bersamasama seluruh kelas, kadang di kelas masing-masing. Karena itulah kelas harus selalu bersih, sepatu dilepas agar tidak ada kotoran ataupun najis. Seperti gambar berikut siswa sedang shalat dhuha berjamaah.

9. Melaksanakan Shalat Berjamaah Dzuhur Dan Ashar Setiap Hari.

Pelaksanaan shalat zuhur dan ashar berjamaah dilaksanakan setiap hari sebagai salah satu cara membiasakan siswa untuk mau shalat berjamaah dan siswa mengetahui pentingnya shalat berjamaah. Seperti gambar berikut siswa sedang shalat berjamaah.

10. Mengadakan Upacara Setiap Hari Senin.

Melaksnakan upacara setiap senin adalah bagian dari menumbuhkan cinta tanah air. Membiasakan anak anak bahwa negara kita Indonesia harus kita jaga dan kita banggakan. Seperti gambar berikut siswa sedang upacara bendera setiap senin. 
Dari hasil pengamatan peneliti pada acara sosialisasi dari pihak sekolah di depan guru, wali murid dan siswa secara online. Sekaligus acara penguatan mental guru, wali murid dan siswa ketika situasi sedang menghadapi covid, ketika pelaksanaan siraman rohani dijelaskan bahwa guru haruslah selalu menekankan dalam amalan baik sehari-hari kepada siswa. Dengan mengingatkan tentang menghormati guru, patuh pada orang tua/birrul walidain agar diterapkan oleh orang tua dengan pola dan konsep pengajaran yang sama. Dengan bahasa yang sama, insyaallah akan menguatkan pemahaman anak dalam mengamalkan Al-Qur'an dan hadistyang dipelajari. Perlu ditegaskan kembali, bahwa birrul walidain (berbakti kepada kedua orang tua), tidak hanya sekadar berbuat ihsan (baik) saja. Akan tetapi, birrul walidain memiliki bakti'. Bakti itu pun bukanlah balasan yang setara jika dibandingkan dengan kebaikan yang telah diberikan orang tua. Namun setidaknya, berbakti sudah dapat menggolongkan pelakunya sebagai orang yang bersyukur dan sabar.

Dari hasil wawancara dengan kepala sekolah, dikatakan bahwa Program Pendidikan Karakter yang dikembangkan di kelas 6 pada tahun pelajaran 2019-2020 adalah sebagai berikut: (a). adab dan akhlak yang mulia, (b). kebersihan lingkungan, (c). sosial masyarakat, (d). kesadaran beribadah.

Sistem Pendidikan Islam yang diselenggarakan di AlWildan adalah Pendidikan yang berparadigma al-Qur'an dan as-Sunnah yang menjadi unggulan sekolah ini. Dari wawancara dengan wali murid 176, alasan menyekolahkan anaknya kesekolah ini adalah ingin anaknya diberi bekal ilmu dan pelajaran al-Qur'an dan sunnah. Karena disini pelajaran alQur'an dan as-sunnahnya maksimal. Anaknya rajin solat, rajin mengaji, akhlaknya bagus, sama orang tua patuh. Bahkan orang tua pun sering diingatkan dengan amalan kebaikan oleh anaknya. Supaya sabar dan syukur. Materi syukur di ulangulang oleh guru dalam keseharian dalam belajar, yang di sinergikan. 
Implementasi Pendidikan Karakter Berbasis al-Qur'an dan as-Sunnah: Studi Kasus Kelas 6 SD al-Wildan Islamic School (NVurul Islam) Tangerang |

\section{E. Faktor Pendukung dan Penghambat Implementasi Pendidikan Karakter}

Berbasis al-Qur'an dan as-Sunnah di Sekolah Dasar (SD) Al-Wildan Islamic School (Nurul Islam) Tangerang.

1) Faktor Pendukung

Berdasarkan hasil wawancara dengan kepala sekolah, penulis menyimpulkan bahwa faktor pendukung dalam implementasi pendidikan karakter berbasis al-Qur'an dan asSunnah di Sekolah Dasar (SD) Al-Wildan ini adalah terletak pada ketaatan dan disiplin guru dalam menjalankan tugas amanah mendidik murid-murid yang di amanahkan disekolah ini, selain itu konsistensi pimpinan, sinergi semua pihak termasuk komite sekolah dan wali murid dalam memenuhi kebutuhan belajar siswa dalam pelajaran beragama Islam secara kaffah. Tanpa dukungan semua pihak tersebut tentu program ini tidaklah bisa berjalan dengan maksimal, dan tentunya kita kuatkan tekad semangat juang membela dan peduli agama Allah, dalam semangat iman dan takwa.

2) Faktor Penghambat

Berdasarkan hasil data wawancara penelitian menyimpulkan bahwa faktor penghambat dalam implementasi pendidikan karakter ini adalah terletak pada bagaimana pihak sekolah melihat ini sebagai sebuah peluang dan tantangan pada saat penerimaan siswa baru yang berkarakter al-Qur'an dan asSunnah, dalam hal ini penerimaan siswa baru Al-Wildan tidak menolak anak yang karakternya kurang baik, dalam hal ini diterima. Karena berdasarkan prinsip semua anak berhak menjadi baik dan berkarakter sesuai Alquran dan sunnah dengan pendidikan karakter maka yang diterapkan di sekolah pun dengan prinsip tentunya atas izin Allah Swt. Demikian pimpinan sekolah menyampaikan. Kemudian disampaikan juga bahwa adapun tantangan siswa baru yang di hadapi cukup bervariasi dan untuk mengatasinya dilakukan pendekatan yang intensif dengan anak, menyesuaikan dengan karakter mereka sebelumnya dan juga menjalin komunikasi intensif dengan orang tuanya. 
Jadi dalam hal ini penulis menyimpulkan bahwa faktor pendukung dan penghambat implementasi Pendidikan karakter berbasis al-Qur'an dan as-Sunnah di SD Al-Wildan Islamic School (Nurul Iman) Tangerang adalah: Faktor pendukung: ketaatan dan disiplin guru dalam menjalankan tugas amanah sebagai pendidik, dan dukungan semua pihak yaitu pimpinan, guru dan komite sekolah, dan wali murid belajar Islam secara kaffah. Tekad dan juang membela dan peduli agama Allah dalam semangat iman dan takwa. Murid dan wali murid yang termotivasi tinggi untuk belajar agama. Faktor penghambat: adanya murid baru yang berkarakter kurang baik. Lingkungan pergaulan murid yang kurang baik. Dukungan orang tua yang lemah pemahaman agama. Ketika orang tua dan murid motivasi beragamanya naik turun. 


\section{F. Penutup}

Setelah membahas tesis dengan judul "Implementasi Pendidikan Karakter Berbasis al-Qur'an dan as-Sunnah (Studi Kasus Kelas 6 SD Al-Wildan Islamic School (Nurul Islam) Tangerang" melalui observasi, wawancara dan dokumentasi, maka peneliti dapat menyimpulkannya sebagai berikut:

Pertama, Pendidikan karakter berbasis al-Qur'an dan AsSunnah di Sekolah Dasar (SD) Al-Wildan Islamic School (Nurul Islam) Tangerang adalah program unggulan sekolah, (a) tujuannya untuk pembentukan karakter mulia sesuai alQur'an dan as-Sunnah padadiri peserta didik melalui pembelajaran sehari-hari di kelas, (b) kurikulumnya adalah 3 kurikulum, yaitu nasional, internasional dan pesantren melalui proses stimulan pendidkan karakter yang lama sejak kelas 1 sehingga di kelas 6 sudah menjadi karakter anak. (c) metode pengajrannya dengan Step an elicit, metode bijak (taat pada Allah dan Rasul-Nya, taat dan hormat kepada guru, dan taat kepada orang tua), dan Quality Qontrol ibadah, dan dengan (d) system evaluasinya dengan penilaian Quality Control (QC) siswa yang ketat, kemudian di nilai dan di tindak lanjuti pada program-program pendukung yaitu pelatihan guru-guru, program sosialisasi, program parent visit class (PVC), program rumah tahfizh, dengan rumusan nilai: (1) Penanaman adab dan akhlak yang mulia, (2) Kebersihan lingkungan, (3) Sosial Masyarakat, (4) Kesadaran beribadah, (5) Cinta tanah air.

Kedua, Implementasi materi pembelajaran terkait pendidikan karakter berbasis al-Qur'an dan as-Sunnah di SD AlWildan Islamic School (Nurul Iman) Tangerang adalah bahwa semua materinya masuk dalam kegiatan sekolah yang terpola khusus, mulai dari kedatangan pagi hari hingga kepulangan siswa, kegiatan tersebut antara lain adalah: (a) Penyambutan siswa saat pagi oleh semua guru, (b) Bimbingan wali kelas 20 menit pertama setiap hari, (c) Membuat tata tertib dikelas, (d) Makan siang bersama guru di kelas, (e) Mengadakan lomba kebersihan dan keindahan kelas, (f) Mengadakan kegiatan bakti sosial untuk anak yatim dan dhuafa, (g) Membaca zikir pagi dan petang tiap hari, (h) Melaksnakan shalat dhuha setiap hari, (i) Melaksnakan shalat zuhur berjamaah, (j), Mengadakan upacara. 
Ketiga, Faktor pendukung dan penghambat implementasi Pendidikan karakter berbasis al-Qur'an dan as-Sunnah di SD AlWildan Islamic School (Nurul Iman) Tangerang adalah sebagai berikut: Faktor pendukung: ketaatan dan disiplin guru dalam menjalankan tugas amanah sebagai pendidik, konsistensi pimpinan, sinergi dan dukungan semua pihak yaitu pimpinan, guru dan komite sekolah, dan wali smurid belajar Islam secara kaffah. Tekad dan semangatjuang membela dan peduli agama Allah dalam semangat iman dan takwa. Guru, wali murid dan murid yang termotivasi tinggi untukbelajaragama. Faktor penghambat: adanya murid baru yang berkarakter kurang baik. Lingkungan pergaulan murid yang kurang baik. Dukungan orang tua ang lemah pemahaman agama. Ketika orang tua dan murid dalam keadaan motivasi beragamanya yang naik turun. Bagi pihak sekolah factor penghambat ini dipandang sebagai sebuah. 


\section{Daftar Pustaka}

Abdullah, Ali, Rasulullah Saw, The Unthold Story, Jakarta: Gramedia, 2015.

Afrina, Nike Gustia, “Model Integrasi Kurikulum Qur'an Sunnah Brain Attitude (Quba) dalam Membentuk Karakter Siswa (Studi Kasus di Madrasah Aliyah Swasta Kulliyatul Mu'allimat el-Islamiyah Diniyyah

Ahmad, Khursyid, Principles of Islamic Education, Lahore: Islamic Publications, 1974.

Ahmad, Marimba, Pengantar Filsafat Pendidikan, cet-VIII, Bandung: PT. Al-Ma'arif, 1989.

Ainain, Ali Khalil Abu, Falsafah at-Tarbiyah fi al-Qur'an al-Karim, alQahirah: Dar al-Fikri al-Arabi, 1985.

Akbar, Reni, dan Hawadi, Psikologi Perkembangan Anak, Mengenai Sifat, Bakat dan kemampuan Anak, Jakarta,Geraiindo, 2003.

al-Atsari, 'Abdullah bin 'Abd al-Hamid, Aqidah Salaf Ahlus Sunnah wal Jama'ah, terj. Ahmad Syaiku, Jakarta: Pustaka Al-Inabah, 2015.

al-Attas, Syed Muhammad Naquib, Islam: Faham Agama dan Asas Akhlak, Kuala Lumpur: Ta'dib Internasional, 2019. al-Bukhari, Imam Al-Adab Al-Mufrad: Kumpulan Hadits Adab dan Akhlak Seorang Muslim, Pensyarah Syaikh Muhammad Luqman As-Salafi, Jilid 2, Jakarta: Griya Ilmu, 2011.

al-Farran, Syaikh Ahmad Musthafa, Tafsir al-Imâm asy-Syafi'i, (Surah An-Nisa'-Surah Ibrahim, terj. Fedrian Hasmand, Fuad S.N., Ghafur S., dan Arya N.A., Jilid 2, Jakarta: Almahira, 2007.

al-Ghazali, Imam, Ihya' Ulmum ad-Din, Juz III, Mesir: Dar Ihya' al-Kutub alArabi, t.th.

Ihya' al-Ghazali, terj. Ismail Yakub, Jilid IV, Jakarta: Faizin, 1986.

Misykat al-Anwar, Kairo: Dar al-Ma'arif, 1964.

al-Hakim, Sayyid Mundzir, 14 Teladan Abadi (1): Muhammad Rasulullah Saw., Sang Adiinsan, terj. Muhammad Alcaff, Jakarta: Nur Al-Huda, 2016.

al-Baihaqi, Abu Bakar Ahmad bin al-Husain bin Ali al-Sunan al-Kubra wa Dzalihi al-Jauhar an-naqi, Jilid 10, alHind: Majlis Dairah al-Ma'arif an-Nizhamiyah alKâinah, 1344 H. 
Implementasi Pendidikan Karakter Berbasis al-Qur'an dan as-Sunnah: Studi Kasus Kelas 6 SD al-Wildan Islamic School (Nurul Islam) Tangerang |

Alhamuddin, Politik Kebijakan Pengembangan Kurikulum di Indonesia: Sejak Zaman Kemerdekaan Hingga Reformasi (1947-2013), Jakarta: Prenamedia Group, 2019.

Ali, Aisyah M., Pendidikan Karakter: Konsep dan Implementasinya, Jakarta: Kencana, 2018.

Al-Qur'an dan Terjemahannya

Amin, Maswardi Muhammad, Memasyarakatkan Budi Pekerti yang Terkandung dalam Gurindam Dua Belas (Raja Ali Haji), Yogyakarta: Absolute Media, 2012.

Amril, M., Etika dan Pendidikan, cet. Ke-1, Yogyakarta: LSFK2P dan Aditya Media, 2005.

Andalusi, Abu Muhammad 'Ali Sa'id bin Hazm al-Ihkam fi Ushul alAhkam, Jilid I, al-Qahirah: Dar al-Kutul alIlmiyah, 1967.

Anees, Bambang \& Adang Hambali, Pendidikan Karakter Berbasis al-Qur'an, Bandung: Simbiosa Rekatama Media 2009.

Ansyar, Mohamad, Kurikulum: Hakikat, Fondasi, Desain dan Pengembangan, cet. ke-2, Jakarta: Kencana, 2017.

Arifin, Bambang Syamsul, Psikologi Agama, cet. ke-2, Bandung: CV. Pustaka Setia, 2015.

Arifin, H.M, Ilmu Pendidikan Islam; Tinjauan Teoritis dan Praktis Berdasarkan Pendekatan Interdisipliner, Edisi Revisi, Jakarta: PT. Bumi Aksara, 2014.

Arikunto, Suharsimi, Prosedur Penelitian Suatu Pendekatan Praktik, Jakarta: Rineka Cipta, 2014.

Asharaf, Ali, dan Sajjad Husain, Pergulatan Idiologis Pendidikan Islam: Refleksi Pendidikan Islam dalam Menemukan Identitas di Era Globalisasi, Terj. Mukani, Malang: Madani Media, 2011.

Badri, Muhammad, Sentuhan Jiwa untuk Anak Kita, Bekasi: Daun Publishing, 2015.

Borba, Michele, Building Moral Intellegence: The Seven Essential Virtues That Kids to Do The Right Thing, 2001. Edisi Bahasa Indonesia: 128.

Chirzin, Muhammad, Kearifan Al-Qur'an, Jakarta: Gramedia Pustaka Utama, 2013.

Dalimunthe, Reza Armin Abdillah, "Strategi dan Implementasi Pelaksanaan Pendidikan Karakter di SMPN 9 Yogyakarta", Jurnal Pendidikan Karakter, Tahun V, No. 1, April 2015. 
Implementasi Pendidikan Karakter Berbasis al-Qur'an dan as-Sunnah: Studi Kasus Kelas 6 SD al-Wildan Islamic School (Nurul Islam) Tangerang |

Damaledo, Yandri Daniel, "Ujian Nasional Dihapus Mendikbud dan Sejarahnya di Indonesia", Artikel berita tanggal 12 Desember 2019, https://tirto.id/enkH, diakses tanggal 1 Juli 2020 jam 14.00.

Daudy, Ahmad, Allah dan Manusia dalam Konsepsi Syiekh Nurudin ar-Raniry, Jakarta: CV Rajawali, 1983.

Elfindri, at.all., Pendidikan Karakter: Kerangka, Metode, dan Aplikasi untuk Pendidik dan Profesional, Jakarta: Baduose Media Jakarta, 2012.

Fitri, Anggi, "Pendidikan Karakter Perspektif al-Qur'an Hadits", dalam Ta'lim: Jurnal Studi Pendidikan Islam, Vol.1 No.2 Juli 2018.

Hakim, Atang Abd., dan Jaih Mubarok, Metodologi Studi Islam, cet. ke-17, Bandung: PT. Remaja Rosdakarya, 2017.

Puteri Padang Panjang Sumatera Barat", Tesis, (Malang: UIN Maulana Malik Ibrahim, 2017), 197, tidak diterbitkan (t.d.). 